\title{
Т.И. Коломиец
}

\section{ИНВЕСТИЦИОННЫЙ ПРОЕКТ КАК ИНСТРУМЕНТ ВЫЯВЛЕНИЯ ПРИОРИТЕТОВ НА РЫНКЕ ТРУДА}

\begin{abstract}
Новым в настоящей статье является подход к инвестиционному проекту как индикатору приоритетов на рынке труда, аккумулирующему ряд системных требований к иелям и условиям реализации инвестиционных решений. Обосновывается, что инвестиционный проект уже на этапе подготовки имеет все основания для включения совокупности технико-технологических, сочиально-экономических и организационных решений, обеспечивающих базу для перераспределения финансовых ресурсов наиболее рациональным способом.

Ключевые слова: проектирование инвестиционных программ, субъекты вложений в основной капитал, карта инвестиционных проектов.
\end{abstract}

Среди составляющих социально-экономического эффекта при реализации новых инвестиционных проектов их инициаторы выделяют создание новых рабочих мест как важнейшего социального ориентира, связанного с повышением качества жизни населения региона.

В региональной социально-экономической политике проектное финансирование пришло на смену процессам выравнивания уровней экономического развития, характерным для периода последнего десятилетия XX в. В Стратегии социально-экономического развития Сибири, утвержденной распоряжением Правительства Российской Федерации от 5 июля 2010 г. № 1120-p, также выражена четкая позиция федерального центра по отношению к проблемам макрорегиона Сибирь. Особенностью действующей версии документа стал акцент на инвестиционный проект, в отличие от поддержки традиционных отраслевых комплексов Сибири как ключевого направления финансирования развития, присущего прежней версии Стратегии.

Для того чтобы мотивировать бизнес и власти территорий на поиск конкурентных преимуществ, а также минимизировать издержки растущей коррупционной составляющей, важнейшие финансовые ресурсы были сконцентрированы в федеральном центре. Их доля в общей сумме налогов и сборов, собранных на местах, превысила 80\%. Регионы, на которые была перенесена основная тяжесть вопросов, связанных со снятием нарастающей социальной напряженности, оказались в сложном финансовом положении.

Если говорить конкретно о налогах, опираясь на пример одного из развитых инновационных регионов СФО, Томской области, то только $29 \%$ суммы, или 41 млрд из собранных в 2015 г. 140 млрд налоговых рублей, было оставлено на территории ${ }^{1}$ [1. С. 1]. Без программ создания новых промышленных и социальных объектов на базе государственно-частного партнерства и значительной доли проектного финансирования со стороны государства выполнение стратегических задач в этих условиях не может быть осуществлено. Закономерно, таким

\footnotetext{
${ }^{1}$ По данным бюджетно-финансового комитета Законодательной Думы области.
} 
образом, что инвестиционный проект становится инструментальным условием сосредоточения технико-технологических, социально-экономических и организационных решений, эффективная реализация которых позволяет перераспределять основные финансовые ресурсы наиболее рациональным способом.

Каждый из 12 субъектов, входящих в Сибирский федеральный округ (и не только они), развивает свои инвестиционные стратегии, сообразуясь с имеющимися природно-ресурсным и социально-экономическим потенциалами. Обобщающим показателем для оценки инвестиционного процесса являются вложения в основной капитал. Определим динамику названных показателей на конкретном примере, для чего проведем с учетом вышеназванных позиций аналитический обзор доступных в пользовательском формате инвестиционных проектов Томской области.

Позиция Томской области в сфере инвестиций в основной капитал по видам экономической деятельности и инвестиций на душу населения может быть определена согласно официальной информации органов государственной статистики Российской Федерации и ее субъектов. К ним относятся затраты на строительство, реконструкцию (включая расширение и модернизацию) объектов, которые приводят к увеличению их первоначальной стоимости, а также затраты на приобретение машин, оборудования, транспортных средств, производственного и хозяйственного инвентаря, на формирование рабочего, продуктивного и племенного стада, насаждение и выращивание многолетних культур.

По данным о структуре инвестиций в основной капитал, измеренных по видам основных фондов в процентах от их общего объема, обнаруживаем следующее. В 2010-2013 гг. область сократила инвестиционные вложения в жилища, здания (кроме жилых) и сооружения, но существенно увеличила вложения в машины, оборудование и транспортные средства $(44,0 \%$ в 2013 г. против 27,5\% в 2010 г.). Это при том, что, согласно усредненным данным по Российской Федерации, в целом показатели вложений в машины и оборудование за период, напротив, сократились, что отражает более выгодную позицию региона.

По доле инвестиций в основной капитал на душу населения (в фактически действовавших ценах) Томская область заняла в 2013 г. 19-е место среди 85 субъектов Российской Федерации, уступив в регионах Сибирского федерального округа только Красноярскому краю, разместившемуся на 14-м месте в РФ.

Однако в 2014 г. к уровню 2013 г. в экономике Томской области наблюдается снижение объема инвестиций в основной капитал в сопоставимых ценах до 95,4\% [2]. При этом в составе инвестиций в основной капитал попрежнему преобладают инвестиции, направленные в деятельность по добыче полезных ископаемых, доля которых в 2014 г. составила 43,5\% от общего объема инвестиций.Правда, индекс физического объема добычи к уровню 2013 г. уменьшился в 2014 г. до 90,2\%.

Согласно данным, опубликованным в начале 2016 г., в области произошло и незначительное снижение индекса промышленного производства: в 2015 кризисном году на 0,6\% по сравнению с 2014 г. [3]. 
Приведенные здесь выборочные данные, раскрывающие объем и динамику инвествложений СФО и Томской области в основной капитал, предваряют анализ имеющихся данных по важнейшим инвестиционным проектам региона, успехи которого в отраслях перерабатывающего сектора признаны очевидными.

Источниковой базой для обзора инвестиционных проектов Томской области могут служить: инвестиционный портал по обмену инвестиционными проектами и предложениями инвесторов «Биржа инвестиционных проектов» [4]; обобщенные и размещенные рейтинговым агентством «Эксперт РА» по данным администраций регионов сведения о крупнейших инвестиционных проектах Сибирского федерального округа; Государственный реестр проектов, получивших бюджетные ассигнования Инвестиционного фонда РФ (Минрегионразвития); инвестиционные проекты и предложения Томской области (Каталог инвестиционных проектов; Каталог инвестиционных предложений), размещенные на официальном портале администрации Томской области [5].

В структуре 100 крупнейших (по необходимому объему инвестиций) из 200 инвестпроектов, выявленных в 2011 г. Expert.ru для реализации на территории Сибирского федерального округа, преобладают такие направления, как транспортная инфраструктура, энергоносители, добыча черных и цветных металлов, лесная промышленность, городское и птицеводческое хозяйства, лечебно-оздоровительные комплексы.

Их суммарное число в Красноярском крае - 17, в Республике Бурятия и Томской области - по 16, в Иркутской области - 13, в Алтайском крае - 9, в Забайкальском крае - 7, в Республике Тыва и Кемеровской области - по 5, в Новосибирской области - 4, в Республике Хакасия - 2. Эти отрасли являются традиционными для инвестпроектов бизнеса в регионах Сибири, что отражает, по мнению экспертов, факт отсутствия эффективного управления инвестиционными процессами на уровне регионов [6].

Вместе с тем исследование Всемирного банка выявило: показатели отдельных субъектов Российской Федерации в период с 2011 г. значительно превосходят результат России, которая представлена Москвой. По ряду этих показателей в числе лидеров - субъекты Сибирского федерального округа. В целом, несмотря на различия в социально-экономическом развитии отдельных регионов, Сибирь позиционируется как территория, привлекательность которой для инвесторов очевидно растет. Важно при этом, что направленность инвестиций не ограничивается сырьевым сектором, что подтверждается стратегическими приоритетами регионов. Администрация Томской области одной из первых в СФО поставила перед собой задачу сменить вектор развития территории с сырьевого на инновационный, и сегодня регион позиционируется как «территория умных инвестиций». Томская область привлекает инвесторов, готовых развивать высокотехнологичные производства в сферах информационно-коммуникационных технологий, приборостроения, разработки новых лекарственных препаратов и материалов для медицины, силовой электроники и энергетики.

Данные к анализу инвестпроектов, реализуемых в России, предоставляет также портал «Инвестиционные проекты России». Данный интернет-ресурс 
позволяет получить доступ к более чем 6000 заявленным к реализации и реализуемым инвестиционным проектам в промышленном и гражданском строительстве с использованием открытых и закрытых источников. Среди открытых - 8000 электронных и печатных СМИ, сайты администраций 85 регионов России; пресс-релизы и вебсайты участников проектов: транскрипты федеральных и региональных телеканалов и радиостанций. Сумма инвестиций по проекту, как правило, составляет более 200 млн руб. Допускается неполная и прогнозная информация. Очевидно, что представленные к презентации на интернет-портале Томской области проекты выполнены с соблюдением заданного обозначенным выше порталом формата.

Безусловно, с точки зрения охвата ключевых отраслей и видов деятельности эти проекты отвечают основным миссии и приоритетам инвестиционных вложений бизнеса и администрации Томской области, с привлечением средств Российской Федерации. Однако непредвзятый взгляд на уже заявленные в инвестпроектах показатели, в основном соответствующие утвержденному стандарту формы заявки, требует дополнительных комментариев.

- Прежде всего, в целом ряде инвестиционных проектов отсутствует важнейшая информация по количеству создаваемых рабочих мест, что может быть подтверждением недостаточной проработанности комплекса взаимосвязанных и скоординированных организационно-технических и инвестиционных условий их реализации. Необходимость или целесообразность внесения в представляемый инвестпроект ряда условий может быть инициирована решением главы администрации региона или муниципального образования и внесена в прилагаемую форму карточки инвестиционного проекта.

Для примера можно сослаться на приложение к Постановлению одного из глав администраций Республики Крым от 24 февраля 2015 г., озаглавленного «Краткое описание инвестиционного предложения (проекта)», где помимо разделов, касающихся общей стоимости, потребностей в инвестициях, источников и форм инвестирования, социальной эффективности и стадий реализации проекта, есть обязательный пункт (№ 11) «создание рабочих мест».

1. Название предложения (проекта).

2. Место реализации предложения (проекта).

3. Общая стоимость (млн руб./ млн. долл. США).

4. Потребность в инвестициях (млн руб./ млн долл. США).

5. Наименование организации - инициатора проекта.

6. Описание проекта.

7. Обеспеченность проекта (наличие земельного участка, имущественного комплекса, собственных средств, технологий и т.д.).

8. Источники и формы инвестирования.

9. Срок окупаемости проекта (лет).

10. Срок реализации проекта (лет).

11. Создание рабочих мест (чел.).

12. Стадия готовности проекта к реализации, текущее состояние, проблемные вопросы.

13. Необходимость государственной поддержки (с указанием формы).

14. Социальная эффективность проекта. 
15. Контактная информация.

Часть подобной информации была оформлена в качестве Приложения к приказу Министерства регионального развития Российской Федерации от 28.02.2012 № 74 [7].

Форма вместе с тем представляется перенасыщенной дополнительными сведениями, требующимися для включения в бизнес-план проекта. Не являясь сторонником обязательного воспроизведения каждого из перечисленных в форме разделов, считаем возможным привести его полностью, тем более что функции упраздненного министерства регионального развития Кабинетом министров РФ было решено сохранить без изменения их сути, но с перераспределением по другим подразделениям. Итак, составными частями типовой карты инвестиционного проекта, согласно Приложению, являются:

1. Полное наименование инвестиционного проекта.

2. Территория реализации инвестиционного проекта.

3. Отраслевая принадлежность.

4. Цель реализации инвестиционного проекта.

5. Целевые индикаторы инвестиционного проекта (в том числе показатели объемов строительства, объемов производства или предоставляемых услуг, количество создаваемых рабочих мест).

6. Участники инвестиционного проекта: координатор(ы), ответственный(ые) исполнитель(ли), инвестор(ы).

7. Срок реализации инвестиционного проекта (в том числе сроки строительства и (или) реконструкции объектов капитальных вложений, сроки выхода на проектную мощность).

8. Стоимость инвестиционного проекта, источники и объемы финансирования инвестиционного проекта.

9. Механизмы оказания государственной поддержки.

10. Перечень объектов капитального строительства, создаваемых в рамках инвестиционного проекта:

- наименование,

- стоимость объекта с разбивкой по источникам финансирования,

- право собственности (государственная, муниципальная, частная и иные формы собственности),

- наличие землеотвода,

- наличие проектной документации (включая смету на строительство),

- наличие заключения государственной экспертизы проектной документации (включая смету на строительство) и результатов инженерных изысканий.

11. Показатели инвестиционной привлекательности проекта:

- дисконтированный срок окупаемости проекта (годы),

- IRR (внутренняя норма доходности, \%),

- NPV (чистая приведенная стоимость проекта, млн. руб.),

- ставка дисконтирования (\%),

- бюджетная эффективность проекта (налоговые поступления в бюджеты всех уровней за период 10 лет, млн руб.).

12. Текущий статус реализации инвестиционного проекта: 
- стадия реализации инвестиционного проекта (предынвестиционная стадия, реализация проекта, завершен),

- освоенные средства (по объектам и источникам финансирования) с указанием объектов, введенных в эксплуатацию.

13. План-график выполнения мероприятий по поддержке и реализации проекта.

- Далее согласно Стратегии социально-экономического развития Томской области до 2030 года, разработанной на основе требований Федерального закона от 28 июня 2014 г. № 172-Ф3 «О стратегическом планировании в Российской Федерации», Закону Томской области от 12 марта 2015 г. № 24-О3 «О стратегическом планировании в Томской области» и другим документам, усилия населения, бизнеса и власти сосредоточиваются на реализации Концепции создания в Томской области инновационного территориального центра «ИНО Томск», утвержденной распоряжением Правительства Российской Федерации от 14 января 2015 г. № 22-р [8].

В прогнозах актуализируется значимость программ подготовки кадров для инновационного развития, а также совершенствования кадровой работы с уже трудоустроенными сотрудниками различных поколений и возрастных групп. Это требует более тесной связи научно-образовательного комплекса и прежде всего крупного бизнеса, работающего на территории Томской области.

Речь идет о крупнейших предприятиях, входящих в десять интегрированных государственных и частных холдингов: НК «Роснефть», «Газпром», «Росатом», ImperialEnergy, СИБУР Холдинг, «РуссНефть» и др. Тройка самых прибыльных предприятий рейтинга также представлена холдинговыми подразделениями: «Томскнефть» (11,99 млрд руб. при рентабельности 12,59\%), «Востокгазпром» (6,08 млрд, или 23,43\%) и «Газпром Трансгаз Томск» (2,27 млрд руб., или 9,17\%). Именно они формируют более $65 \%$ доходов региона [9].

То же касается развития резидентов Томской экономической зоны, особенно в секторе информационных технологий и электроники. Среди них динамично развивающиеся «МэйнКонцепт-ДивИкс» (разработчик видеокодеков, 66 млн руб. в 2011 г., прирост - 39,3\%), подразделения томских групп «Элекард» («Элекард Девайсез», решения в цифровых технологиях, 72,7 млн руб., 34,8\%) и «ЭлеСи» («ЭлеТим», интеллектуальные электроприводы, 39,8 млн руб., 25\%), и небольшие - ТНИИ «Проект» (разработка компонентов ИТ-платформ, 2,98 млн руб., 39,5\%), «Центр беспроводных технологий» (телеком-оборудование для сетей LTE, 0,5 млн руб.), а также и снизившие доходы - «Монсун Мультимедиа» (разработка устройств для цифрового телевидения, 7,8 млн руб., -10,1\%) и «Эмишэн» (разработка ИТ-средств мониторинга за земной корой) и др. [10].

К сожалению, о потребностях этих групп компаний в кадрах квалифицированных специалистов мало известно на территории, во всяком случае тем, кто непосредственно связан с подготовкой этих кадров. Опыт крупнейших компаний, работающих в экономике РФ в целом, и более широко популяризируемый в научной и периодической литературе мог бы сыграть в этом отношении позитивную роль. 
ОАО «НК «Роснефть» планирует расширить свои функции в реализации совместных образовательных программ с вузами путем участия в независимой оценке эффективности преподавателей профильных вузов и развить систему стимулирования лучших преподавателей, занимающихся ценной для компании научной деятельностью, через выделение грантов, направление на международные стажировки и т.д.

В Паспорт программы инновационного развития ОАО «НК «Роснефть» в 2011 г. также была включена организация производственной практики и стажировок для более 3500 студентов из вузов-партнеров компании ежегодно.

Итак, ОАО «НК «Роснефть» также активно сотрудничает с вузами в подготовке инженерных кадров по специальностям, востребованным в компании, организуя долгосрочные (1-2 года) стажировки магистрантов вузовпартнеров по профилю получаемого образования [11].

- Наконец, при составлении заявки по инвестпроекту важнейшим условием является учет сопряженных эффектов его реализации, касающихся технико-технологических и социально-экономических параметров. Еще на первой ступени формирования совместных с государством программ финансирования инвестпроектов регионов (2010-2011 гг.) эффект социальной стабильности оценивался как создание новых рабочих мест и заработная плата новых и занятых работников. В Минрегионе было заявлено о намерении получить 130 тыс. рабочих мест по проектам общегосударственного значения, которые уже начали осуществляться, и по 23 отобранным региональным проектам - еще более 30 тыс.

Обратимся к инвестиционным проектам Томской области.

Ниже приведем перечень инвестпроектов Томской области, информация по которым размещена на сайте обладминистрации. Дата размещения - май 2015 г. Выбор осуществляем по принципу максимально заявленных объемов финансирования, с выделением объектов инвестирования, по которым указано количество создаваемых рабочих мест.

Среди крупнейших 8 проектов выявляем объекты инвестирования, по которым указано количество создаваемых рабочих мест. Таковых оказывается всего три:

- проектирование и строительство горно-обогатительного комбината по производству циркониевого, ильменитового, рутил-лейкоксонового концентратов и кварцевого песка для стекольной промышленности при сметной стоимости проекта 5 280,00 млн руб. и предполагаемом количестве занятых 204;

- добыча углеводородного сырья ОАО «Томскгазпром», сметная стоимость проекта - 84 620,00 млн руб., количество создаваемых рабочих мест 316;

- создание современного завода по производству древесно-стружечных плит мощностью 350 тыс. куб. м/год. Увеличение объема лесозаготовок до 1 млн куб. м/год. Сметная стоимость проекта - 5 400,00 млн руб., количество создаваемых рабочих мест - 560 .

При этом обзор приведенных инвестпроектов не позволяет обнаружить данные, включающие профессионально-квалификационные требования к претендентам на рабочие места. Это может служить косвенным признаком 
отсутствия программ финансирования объектов инфраструктуры, привлекающих немало кадров сопровождения и обслуживания как на стадиях строительства, так и стадиях эксплуатации площадей.

Между тем задача создания 25 млн новых, высокотехнологичных, хорошо оплачиваемых рабочих мест для людей с высоким уровнем образования к 2020 г. не снята с повестки.

Опросы инвесторов подтверждают, что самым сложным вопросом для регионов в части привлечения инвестиций является развитие инфраструктуры, практически все регионы СФО имеют слабую собственную финансовую базу, если говорить о бюджетных средствах и развитии банковского сектора, доступность ресурсов которого практически не зависит от региональных властей.

Определяемый согласно методологии АСИ национальный рейтинг состояния инвестиционного климата в субъектах Сибирского федерального округа может быть воспринят только как один из возможных ориентиров при принятии решений. В нем, по результатам расчета интегрального рейтинга, Томская область занимает 8-е место среди субъектов Федерации, после Калужской, Ульяновской областей, Красноярского края, Республики Татарстан, Костромской области, представивших первую группу регионов с самыми высокими оценками, а также Тульской области и Краснодарского края, вошедших во вторую группу по итогам 2014 г. [12].

Отсюда следует, что инвестиционные проекты, развиваемые, в частности, Томской областью, нуждаются в более выверенных и точных оценках реальных и потенциальных потребностей в финансовых ресурсах, объектах инфраструктуры, формирующих мультипликативные эффекты вложений в проект. Тем более, с учетом потребностей сектора образования, ориентированного на подготовку высококвалифицированных специалистов.

Выводы. Проектное финансирование развития территорий, пришедшее на смену финансирования развития традиционных отраслевых комплексов Сибири, стало важнейшим инструментом реализации Стратегии социальноэкономического развития СФО и Томской области в составе Российской Федерации. Инвестпроекты требуют максимальной ориентации на развитие высокопроизводительных видов деятельности, повышение занятости и уровня жизни на всей территории региона.

В настоящее время качество заявляемых в инвестпроектах параметров развития не соответствует новым потребностям рынка труда и рынка образовательных услуг. На стадии разработки инвестиционных проектов должны быть проведены оценочные прогнозные расчеты сроков окупаемости, выявляться целевые индикаторы (в том числе показатели объемов строительства, объемов производства или предоставляемых услуг), а также количество создаваемых рабочих мест.

Наблюдение в формате инвестиционного обзора следует переводить на уровень расчетов прямых и косвенных (сопряженных) эффектов от реализации проектов. Этап проектирования объектов для инноваций пора дополнять исследованиями на этапе прогнозирования с использованием наработанных в теории макроэкономики и теории регионального хозяйствования методов. В частности, на примере разработок, проводимых учеными Сибири и Дальнего 
Востока с использованием матрицы социальных счетов региона. Разработанная ими на примере Хабаровского края структурная модель ориентирована на оценку прямых и косвенных связей отраслей топливно-энергетического комплекса с экономикой региона, что делает ее приемлемой для расчетов на уровне сырьевых отраслей экономики СФО. Проведение прогнозных расчетов должно стать, при заинтересованности инвесторов, предметом прогнозирования развития территорий, с включением в расчет потребностей регионов СФО и Томской области, в частности, в кадрах высокой квалификации.

Карта инвестиционного проекта должна выстраиваться с учетом прогнозных параметров спроса и существующего качества и предложения рабочей силы, в перспективе дополняться оценкой необходимых профессиональных компетенций кандидатов на новые рабочие места.

\section{Лumepamypa}

1. Верно расставить приоритеты: Об искусстве бюджетной навигации во время финансового штиля // Красное знамя [газ.]. 2015. 24 дек. № 186.

2. Индекс производства в Томской области незначительно сократился [Электронный реcypc]. URL: http://fedpress.ru/news/econom/industry/ (дата обращения: 27.01.2016).

3. Сведения об инвестиционной деятельности в Томской области за 2014 год: стат. бюл. Томск, 2015.

4. Инвестищионные проекты Томской области [Электронный pecypc]. URL: http://www.inproex.ru/send

5. http://invest.tomsk.gov.ru/Tomsk-region-investments-projects-and-proposals

6. Эксперт Сибирь [Электронный ресурс]. Эксперт Сибирь.

7. Об утверждении типовой формы карты инвестиционного проекта: Приказ Минрегиона РФ от 28.02.2012 № 74 [Электронный pecypc]. URL: http:// www.consultant.ru/cons/ document/cons_doc_LAW_128096/

8. Об утверждении Стратегии социально-экономического развития Томской области до 2030 года [Электронный ресурс]. URL: http://docs.cntd.ru/document/467920053

9. Томская область - территория экспортного развития // Инвестиционный портал Томской области. URL: http://rcsme.ru/ru/news/show//09-11-2015 (дата посещения: 10.03. 2016).

10. Поиск разгонного блока // АЦ «Эксперт-Сибирь» [Электронный ресурс].. URL: http://expert.ru/siberia/2013/ 19/poisk-razgonnogo-bloka/

11. Паспорт Программы инновационного развития ОАО «НК «РОСНЕФТЬ» [Электронный pecypc]. URL: http://www.rosneft.ru/attach/0/02/ 03/ passport_pinr.pdf

12. Национальный рейтинг состояния инвестиционного климата в субъектах РФ / Электронный ресурс. URL: http://www.investinregions.ru/rating/ а также http://asi.ru/ upload_docs/ Rating2014.pdf

Kolomiets T.I. Tomsk State University (Tomsk, Russia). E-mail: tkolom@yandex.ru THE INVESTMENT PROJECT AS AN INDICATOR OF THE PRIORITIES IN THE LABOR MARKET.

Keywords: design of investment programs, investors in fixed assets, investment projects map.

The article presents a new approach to the investment project as an indicator of the priorities in the labor market. The author shows that it accumulates a number of system requirements for the goals and terms of the implementation of investment decisions. It is proved that the investment project is in the preparatory phase has every reason to include the aggregate technical and technological, socioeconomic and organizational solutions. These solutions provide the basis for the redistribution of financial resources in the most rational way. 


\section{References}

1. Vernorasstavit' prioritety: $\mathrm{Ob}$ iskusstvebjudzhetnojnavigaciivovremjafinansovogoshtilja // Krasnoeznamja [gaz.] 2015. 24dek. № 186. S.1.

2. Indeksproizvodstva v Tomskojoblastineznachitel'nosokratilsja [Jelektronnyjresurs] URL: http://fedpress.ru/news/econom/industry/ 27.01.2016

3. Svedenijaobinvesticionnojdejatel'nosti v Tomskojoblastiza 2014 god / Statisticheskijbjulleten'. Tomsk, 2015.

4. InvesticionnyeproektyTomskojoblasti / Jelektronnyjresurs. URL: http://www.inproex.ru/send

5. http://invest.tomsk.gov.ru/Tomsk-region-investments-projects-and-proposals

6. JekspertSibir'/ Jelektronnyjresurs: JekspertSibir', № 1 (316)

7. $\mathrm{Ob}$ utverzhdeniitipovojformykartyinvesticionnogoproekta // PrikazMinregiona RF ot 28.02.2012 N 74 [Jelektronnyjresurs]

URL: http://www.consultant.ru/cons/document/cons_doc_LAW_128096/

8. Ob utverzhdeniiStrategiisocial'no-jekonomicheskogorazvitijaTomskojoblasti do 2030 goda [Jelektronnyjresurs] URL: http://docs.cntd.ru/document/467920053

9. Tomskaja oblast' - territorijajeksportnogorazvitija //Investicionnyj portal Tomskojoblasti URL: http://rcsme.ru/ru/news/show//09-11-2015. Data poseshhenija 10.03. 2016

10. Poiskrazgonnogobloka//AC «Jekspert-Sibir'» Jelektronnyjresurs. URL:

http://expert.ru/siberia/2013/19/poisk-razgonnogo-bloka/

11. PasportProgrammyinnovacionnogorazvitija OAO «NK «ROSNEFT"»/ Jelektronnyjresurs. URL: http://www.rosneft.ru/attach/0/02/03/passport_pinr.pdf

12. Nacional'nyjrejtingsostojanijainvesticionnogoklimata $\mathrm{V}$ sub\#ektah RF/ Jelektronnyjresurs: http://www.investinregions.ru/rating/a takzhe http://asi.ru/upload_docs/Rating2014.pdf 